\title{
Modalidades assistenciais de atendimento ao idoso: revisão da literatura*
}

\section{Assistance modalities of attendance to elderly: literature review}

Eduardo Barros de Aquino' Linconl Agudo Oliveira Benito ${ }^{2}$
Recebido em: 07/08/2015.

Aprovado em: 17/10/2016.

1 Acadêmico do $10^{\circ}$ semestre do curso de Enfermagem do Centro Universitário de Brasília UniCEUB. Faculdade de Ciências da Educação e Saúde - FACES. E-mail: edudibarros0987@ gmail.com.

2 Mestre em Gerontologia pela Universidade Católica de Brasília (UCB). Professor do Centro Universitário de Brasília - UniCEUB.

\section{Resumo}

A população idosa e o processo de envelhecimento humano vêm se tornando a cada dia mais presente no cenário mundial ao longo da segunda metade do século XX, alcançando uma verdadeira explosão gerontológico em sua última década. O objetivo da pesquisa apresentada nesse artigo foi evidenciar as modalidades de atendimento ao idoso em ambientes diversos de assistência qualidade. Este estudo trata-se de uma revisão bibliográfica e, para obtenção dos dados e produção da pesquisa, foi realizada a verificação de fontes bibliográficas variadas disponíveis, dando foco principal em estudos extraídos de artigos de periódicos científicos. Na seleção de 12 artigos analisados, obteve-se valores médios de $25 \%$ para o trabalho desenvolvido em instituições domiciliares e $25 \%$ hospitalares, em instituições asilares 16,6\% e 8,33\% para todos de temática ambulatorial, pré-hospitalar, saúde bucal e a humanização cada. O poder público necessita com urgência da elaboração de projetos voltados ao idoso, criando acessibilidade ao mercado de trabalho que se encontra limitada a essa população, dando mais participação, melhorando a qualidade da assistência em saúde e garantindo, assim, a cidadania e vida adequada que o público da terceira idade tanto necessita e merece.

Palavras-chave: Atendimento. Assistência. Qualidade. Idoso.

\begin{abstract}
The aging population and the human aging process are becoming every day more present on the world stage during the second half of the 20th century, reaching a real gerontological explosion in his last decade. The objective of this research was to present the forms of senior care in diverse environments of quality care. This study deals with a literature review and data collection and production survey was conducted to check various bibliographical sources, giving primary focus on studies drawn from scientific journals articles. In the selection of 12 articles analyzed, gave average values of $25 \%$ for work at home institutions and $25 \%$ hospitals, in nursing homes $16.6 \%$ and $8.33 \%$ for all outpatient theme, pre-hospital, health buccal and each humanization. The government urgently needs the development of projects aimed at the elderly, creating accessibility to the labor market which is limited to that population, giving more participation, enhancing the quality of health care and ensuring citizenship and proper life that the public seniors both needs and deserves.
\end{abstract}

Keywords: Assistance. Quality. Treatmant. Elderly. 


\section{Introdução}

A população idosa e o processo de envelhecimento humano vêm se tornando a cada dia mais presente no cenário mundial ao longo da segunda metade do século $\mathrm{XX}$, alcançando uma verdadeira explosão da gerontologia na última década. Esse interesse se traduziu na constituição de centros de estudo e de formação de profissionais voltados para trabalhar com idosos, na abertura de espaços para reuniões e discussões sobre essa temática e na criação de áreas especificamente voltadas para o estudo do envelhecimento, no interior de disciplinas acadêmicas plenamente constituídas (PRADO et al., 2004)

Até 2025, segundo a OMS, o Brasil será o sexto país do mundo em número de idosos. Ainda é grande a desinformação sobre a saúde dessa população e as peculiaridades e desafios que o envelhecimento populacional ocasionará em nosso contexto social. Entre 1980 e 2000, a população com 60 anos ou mais cresceu 7,3 milhões, totalizando mais de 14,5 milhões em 2000. Esse aumento na expectativa de vida, no entanto, precisa ser acompanhado pela melhoria ou manutenção da saúde para que haja uma melhor qualidade de vida (OPAS, 2005).

Com a chegada do processo de senescência, as mudanças anatômicas são, principalmente, as mais visíveis e primeiramente identificadas. A pele que diminui sua hidratação e resseca, tornando-se mais sensível e quebradiça, pálida, perde todo brilho natural da juventude. Os cabelos embranquecem e começam a cair de forma acentuada não sendo mais substituídos naturalmente, principalmente no sexo masculino (NETTO, 2004).

Na concepção de Vieira (1996) e Lopes (2000), os processos de envelhecimento se iniciam desde a concepção, sendo, então, a velhice definida como um processo dinâmico e progressivo no qual ocorrem modificações, tanto morfológicas, psicológicas, funcionais e bioquímicas, que determinam a progressiva perda da capacidade do indivíduo de adaptação ao meio ambiente, tornando-se mais propício à processos patológicos.

O Brasil hoje é um jovem país grisalho. Todo ano, 650 mil novos idosos são inseridos na população brasileira, sendo a maior parte com comorbidades crônicas e alguns com certas limitações funcionais. Em menos de 40 anos, passamos de um cenário de mortalidade de uma população jovem para um quadro de patologias complexas, comuns à terceira idade, caracterizado por doenças crônicas degenerativas e múltiplas, que exigem uma as- sistência constante com medicação e exames periódicos. O número de idosos passou de 3 milhões, em 1960, para 7 milhões, em 1975, e 17 milhões em 2006, um aumento de 600\% em menos de cinquenta anos (VERAS, 2007).

A Lei no 8.842 de 4 de janeiro 1994, que estabelece a Política Nacional do Idoso (BRASIL, 1994), posteriormente regulamentada pelo Decreto No 1.948 de 3 de Julho de 1996 (BRASIL, 1996) tem por finalidade assegurar direitos sociais que garantam a promoção da autonomia, integração e participação efetiva do idoso na sociedade, de modo a exercer sua cidadania. Tendo como seus princípios regidos no art. $3^{\circ}$ a política, a família, a sociedade e o estado têm o dever de assegurar ao idoso todos os direitos da cidadania, garantindo sua participação na comunidade, defendendo sua dignidade, bem-estar e o direito à vida.

As políticas públicas governamentais existentes no Brasil têm procurado desenvolver e implantar modalidades de atendimento aos idosos tais como, Centros de Convivência - espaço que são direcionados para a realização de práticas culturais, de atividade física, educativa, social e de lazer, como forma a proporcionar um crescimento e participação em todo o contexto social em que esse idoso possa está inserido (MENDES, 2005).

Nesse sentido, as redes estaduais de assistência à saúde do idoso propostas pela Portaria GM/MS de número 702/2002 e ainda, a Portaria SAS/MS de número 249/2002, se compõe por instituições hospitalares gerais e por centros de referência em assistência à saúde integral da pessoa idoso (BRASIL, 2002; BRASIL, 2002).

As modalidades de atendimento a pessoa idosa são a internação hospitalar, o atendimento ambulatorial especializado, o hospital-dia e a assistência domiciliar (FERREIRA; BANSI; PASCHOAL, 2014; LOUVISON; BARROS, 2009).

Sendo assim, o objetivo dessa pesquisa foi apresentar as modalidades de atendimento ao idoso em ambientes diversos de assistência observando a qualidade.

\section{Metodologia}

Segundo Houaiss (2004) a metodologia é o ramo da lógica que se ocupa dos métodos das diferentes ciências. Parte de uma ciência que estudo os métodos aos quais ela própria recorre em literatura investigação e estudo, segundo métodos específicos dos componentes e do caráter subjetivo de uma narrativa sistemática. Este estu- 
do trata-se de uma revisão bibliográfica que se caracteriza por ser uma análise crítica, meticulosa e ampla das publicações correntes em uma determinada área do conhecimento de natureza exploratória com forma de abordagem quantitativa descritiva que usou materiais de cunho bibliográfico, para sua criação voltada para apresentação das formas assistências de atendimento a população idosa no Brasil.

O estudo exploratório quanto ao conceito de pesquisa exploratória, da forma como é tradicionalmente entendida, é melhor descrito por Theodorson e Theodorson (1970). Em geral, o principal objetivo é familiarizar-se com um fenômeno que é investigar, de modo que o grande estudo a seguir, possa ser projetado com maior compreensão e precisão. $\mathrm{O}$ estudo exploratório (que pode usar uma grande variedade de técnicas, geralmente com uma pequena amostra permite que o investigador para definir seu problema de pesquisa e formular sua hipótese com mais precisão. Ele, também, permite-lhe escolher a mais (PIOVESAN; TEMPORINI, 1995).

Para obtenção dos dados e produção da pesquisa, foi realizada a verificação de fontes bibliográficas variadas disponíveis (publicações periódicas e impressos diversos) dando foco principal em estudos extraídos de artigos de periódicos científicos. Foi utilizado como base de dados eletrônicas o Scientific Electronic Library Online (SciELO), Base de Dados de Enfermagem (BDENF), Google Schoolar, Literatura Latino-Americana e do Caribe de Informação em Ciências da Saúde (LILACS) e Medical Literature Analysis and Retrieval System Online (MEDLINE). E quanto aos Descritores em Ciências da Saúde (DeCS) usados para a busca de artigos de periódicos científicos tivemos: unidade de internação, tempo de internação, hospitalização, idoso, qualidade, saúde do idoso e institucionalizado.

Os artigos escolhidos e selecionados pela estratégia de busca foram avaliados, pelo pesquisador, obedecendo, rigorosamente, aos critérios de inclusão: pesquisas bibliográficas originais disponibilizadas na forma online e completa, com foco no idoso como público-alvo e nas suas formas diversas de atendimento em saúde, abordando, também, a qualidade desse atendimento segundo a visão do idoso ou dos autores dos estudos, delimitando seu ambiente de análise para atenção pré-hospitalar, hospitalar, ambulatorial e domiciliar, além da Estratégia Saúde da Família (ESF), as Instituições de longa permanência asilar, a saúde bucal do idoso, o atendimento humanizado sendo realizada a coleta de dados entre agosto de 2014 a abril de 2015, nos idiomas (português, inglês) publicados entre os anos de 2003 a 2015.

\section{Resultados e discussão}

Em relação ao levantamento realizado pelos descritores, chegou-se ao quantitativo total de 33 artigos, sendo que deles 36,40 ( $\mathrm{n}=12)$ foram encontrados pela base Literatura Latino-Americana e do Caribe de Informação em Ciências da Saúde (LILACS), 12,10\% (n=04) na base de dados Medical Literature Analysis and Retrieval System Online (MEDLINE), 12,10\% ( $\mathrm{n}=04)$ pela base Base de Dados de Enfermagem (BDENF), 3\% ( $\mathrm{n}=1$ ) Google School e 36,40\% ( $n=12)$ na base de dados Scientific Electronic Library Online (SciELO), conforme exposto juntamente à Tabela 1 .

Tabela 1 - Frequência de artigos adquiridos após levantamento bibliográfico eletrônico, por base de dados e percentual $(n=33)$ :

\begin{tabular}{|c|c|c|}
\hline Base de dados & Frequência & $\%$ \\
\hline Lilacs & 12 & 36,4 \\
\hline Medline & 04 & 12,1 \\
\hline Bdenf & 04 & 12,1 \\
\hline Scielo & 12 & 39,4 \\
\hline Google Schoolar & 01 & 3 \\
\hline Total & 33 & 100 \\
\hline \multicolumn{3}{|c|}{ Fonte: Produção do autor do estudo. } \\
\hline \multicolumn{3}{|c|}{ Após a seleção foram excluídos 21 artigos seguin- } \\
\hline \multicolumn{3}{|c|}{ do os critérios de inclusão e exclusão estabelecidos, ana- } \\
\hline \multicolumn{3}{|c|}{ lisados para a revisão bibliográfica, 12 trabalhos que esta- } \\
\hline \multicolumn{3}{|c|}{ vam diretamente relacionados a formas de atendimento } \\
\hline \multicolumn{3}{|c|}{ ao idoso em modalidades assistenciais diversas. } \\
\hline \multicolumn{3}{|c|}{ Os idosos envolvidos na pesquisa possuem idade } \\
\hline \multirow{2}{*}{\multicolumn{3}{|c|}{$\begin{array}{l}\text { de } 60 \text { anos ou mais de ambos os sexos, tendo, também, } \\
\text { presente no estudo instituições asilares, hospitais da }\end{array}$}} \\
\hline & & \\
\hline \multirow{2}{*}{\multicolumn{3}{|c|}{$\begin{array}{l}\text { rede pública, atendimento pré-hospitalar móvel, am- } \\
\text { bulatorial, estratégia saúde da família (ESF), unidade }\end{array}$}} \\
\hline & & \\
\hline \multicolumn{3}{|c|}{ básica de saúde (UBS) e atendimento domiciliar $\mathrm{AD} /$} \\
\hline \multicolumn{3}{|c|}{ HC (home care), todos estes com assistência voltada } \\
\hline
\end{tabular}
a terceira idade apresentando com um total em média conforme a Tabela 2 . 
Tabela 2 - Frequência de artigos sobre atendimentos realizados às pessoas idosas em vários modelos assistenciais:

\begin{tabular}{lcc}
\hline Tipo de atendimento & Frequência & $\%$ \\
\hline Hospitalar & 03 & 25 \\
Domiciliar & 03 & 25 \\
Asilar & 02 & 16,67 \\
Ambulatorial & 01 & 8,33 \\
Humanização & 01 & 8,33 \\
Pré-hospitalar & 01 & 8,33 \\
Saúde bucal & 01 & 8,33 \\
\hline Total & 12 & 100 \\
\hline Fonte: Produção do autor do estudo.
\end{tabular}

Na seleção de 12 artigos analisados, obteve-se valores médios conforme apresentando na tabela 2, dando um total em porcentagem de $25 \%$ para o trabalho desenvolvido em instituições domiciliares e 25\% hospitalares. O segundo maior tema abordado foi de atendimento ao idoso em instituições asilares totalizando $16,6 \%$. E em terceiro lugar nos achados, tivemos porcentagens iguais para todos de temática ambulatorial, pré-hospitalar, saúde bucal e a humanização voltados ao idoso com $8,3 \%$ cada, o que se obtém um baixo número de publicações nas bases de dados citadas com a temática abordada.

O artigo desenvolvido sobre a efetividade da execução de um fluxo de acesso e definição de prioridades para atendimento ao idoso em um ambulatório mostrou que a aplicação desse método de triagem traria eficiência na assistência ao idoso, pois, obteriam por meio das divisões dos subgrupos, a hierarquização dos riscos fazendo, com que o atendimento seja planejado e direcionado de forma adequada garantindo qualidade na prestação do serviço de saúde abrindo caminhos para a implantação nos atuais ambulatórios do Brasil (VERAS, 2003).

Floriani e Schramm (2004) realizaram um estudo focado no ponto de vista moral abordando a questão ética do atendimento domiciliar. Os idosos apresentados na pesquisa possuíam patologias terminais como cânceres além de doenças crônicas como diabetes mellitus (DM), e, assim, os autores avaliaram que os cuidados administrados AD/HC exprimem questão bioéticas de grande importância, pois nessa assistência há risco de efeitos ir- reversíveis ou inesperados sobre o público-alvo que são os idosos, além de envolver seus cuidadores e a família.

$\mathrm{O}$ atendimento domiciliar vem crescendo a cada dia, famílias optam por manterem os idosos sob seus próprios cuidados com ajuda de cuidadores e equipes de $\mathrm{AD} / \mathrm{HC}$. Um público tão crítico que possui um leque de necessidades complexas que demanda uma assistência de eficiente pois, se esta não for adequada, as consequências podem ser irreversíveis e muitas vezes a elevação na quantidade do cuidado não prioriza a qualidade dessa assistência e a maior vítima é o idoso.

Martin (2007) apresenta um trabalho, também, voltado à assistência domiciliar ao idoso avaliando qual a necessidade educativa apresentada aos cuidadores. Os avaliados possuíam pacientes com condições clínicas múltiplas (CCM) como doença pulmonar obstrutiva crônica (DPOC), hipertensão arterial sistêmica (HAS) entre outras e como resultado relata que as principais necessidades educativas dos cuidadores para com seus pacientes estavam relacionadas às doenças e seus agravos, à terapia medicamentosa, dietas e exercícios físicos.

A educação em saúde é um dos papeis da equipe de enfermagem, em especial do enfermeiro que tem a responsabilidade de passar as orientações aos seus pacientes assim como os idosos e seus acompanhantes. Nesse sentido, é necessário que essa abordagem seja efetiva e autorrefletida pelos profissionais de saúde de como fazer e o que fazer para que a interação enfermeiro/cuidador seja benéfica e as informações passadas possam realmente ser favoráveis e executadas no processo do cuidar.

Foi selecionado um (01) artigo que apresenta a avaliação da qualidade no atendimento ao idoso hospitalar. Os resultados da pesquisa apresentada revelam que 20,18\% das internações são de idosos e 22,12\% dos dias de permanência internados e 29,06\% dos custos com esse atendimento especializado. Segundo autor do ponto de vista epidemiológico, o envelhecimento populacional e mudanças no estilo de vida levarão a uma verdadeira "epidemia" de enfermidades nas próximas duas décadas e conclui que as políticas públicas de saúde precisam ser reavaliadas e começar a tratar as pessoas senescentes como um grupo populacional especial (MARTIN et al., 2006).

Outro estudo selecionado avalia esse atendimento ao idoso no Brasil monitorando a taxa de mortalidade em internações de idosos em 17 hospitais, como forma de avaliar a qualidade da assistência. Utilizando para coleta de dados o Sistema de Informações de Internações Hos- 
pitalares do Sistema Único de Saúde (SIH-SUS). Obtiveram como resultado taxas variadas de 18 a 194 óbitos de idosos por $1.000 \mathrm{AIH}$-mês, sendo identificados hospitais com taxas de mortalidade altas e persistentes, no período estudado (GUERRA; GIATTI; LIMA-COSTA, 2004).

Quem exige do sistema um maior número de intervenções e complexidade no cuidado geralmente são as pessoas na terceira idade por conta do seu processo de envelhecimento que vem atrelado as mudanças e vulnerabilidades. Observar que existem altas taxas de mortalidade nos leva a refletir sobre se essa assistência está sendo eficaz, o que esses dados de mortalidades presentes em instituições hospitalares sinalizam e se são um número esperado ou há nesse processo algum tipo de imprudência, imperícia ou negligencia.

Foi de importância abordar a temática do atendimento ao idoso pré-hospitalar móvel e fixa vítima de acidentes e violência, sendo o atendimento móvel uma forma assistencial muito utilizada por esse público. Obtiveram-se como resultados que quase metade dos serviços pré-hospitalares prestava suporte aos idosos, vítimas de acidentes e violência, o estudo utilizou como parâmetros o que é preconizado pelas principais políticas públicas de atenção à saúde e proteção dos direitos da pessoa idosa (DESLANDES; SOUZA, 2010).

$\mathrm{O}$ atendimento móvel de urgência existente no Brasil é o SAMU, uma forma de assistência muito utilizada por toda a faixa etária. São notificados casos de violência e maus tratos contra idosos o que vem a ser de importância a sua observação, pois as perdas fisiológicas somadas às condições clínicas múltiplas (CCM) levam a quadros de evolução clínicas agudas com complicações muitas vezes irreversíveis. O idoso não pode estar sujeito a obstáculos que possa interferir nessa assistência. São situações que devem ser reavaliados e assim otimizados para que não justifique qualquer tipo de imprudência relacionado ao atendimento.

Entrevistados dos serviços pré-hospitalar (PH) fixo relataram que, inicialmente, se deparam com a dificuldade na identificação dos maus-tratos referindo à dinâmica familiar. Revela que é rotineiro o idoso sentir-se envergonhado de mostrar a real situação ou tentar proteger o filho/ filha ou outro cuidador das responsabilidades pelas violências praticadas. O quadro se torna aí mais grave quando o idoso é um usuário de drogas ou portador de transtorno mental (DESLANDES; SOUZA 2010).

Assim, avaliamos que não há qualquer estudo que nos apresente qualidade com excelência no atendimento prestado ao idoso, pois, em todos, se observam a necessidade melhorias, lacunas existentes, obstáculos a ser superados que envolvem desde a estrutura física até a política pública norteadora à equipe multidisciplinar, o que se torna preocupante diante do alto índice de crescimento de pessoas entrando grupo da terceira idade que o Brasil vivencia.

Seguindo a análise do estudo proposto sobre as modalidades assistenciais do atendimento ao idoso, constatou-se a necessidade realizar comparativos das pesquisas selecionadas com relação à satisfação na qualidade da assistência prestada nas instituições de longa permanência, asilos, nas hospitalares, além do atendimento domiciliar tanto pelos cuidadores de seus pacientes idosos quanto pela estratégia saúde da família (ESF). Reapresentando, como já mencionado anteriormente, a atenção ao idoso vítima de violência acidentes e maus tratos, comumente discutida além de saúde bucal e a como a humanização se encontra em todo esse sistema, conforme apresentado no Quadro 1.

O estudo feito por Bayliss et al. (2015) foi proposto para avaliar a qualidade da assistência através da implantação de um sistema de continuidade do cuidado integrado, com a implantação desse sistema, observou-se ter eficiência e qualidade no que diz respeito a assistência prestada ao idoso no atendimento primário e especializado no EUA, ou seja, torna-se satisfatória a implantação desse tipo de mecanismo no nível primário e demais níveis de assistência do SUS aqui no Brasil já que em países desenvolvidos já se faz presente e com excelência.

Já no estudo feito por Martin et al. (2006), a assistência hospitalar prestada ao público da terceira idade foi considerada satisfatória. Nesse trabalho, ele utilizou o número de internações para fazer sua análise, porém pela idade dos sujeitos da pesquisa serem já bem avançadas além do nível de escolaridade baixo, a qualidade de resultado dito como satisfatório torna-se questionável além do que o próprio autor relata da necessidade de se evitar o processo de internação devido aos riscos expostos e propõe reestruturação do sistema.

A elevação no quantitativo de idosos implica um maior número de problemas de longa duração, pois, geralmente, exigem intervenções de elevado custo, abrangendo tecnologia complexa para uma assistência adequada (VERAS, 1994, 2001). Em menos de 40 anos, o Brasil passou de um perfil de mortalidade típico de uma população jovem para um quadro de enfermidades complexas e onerosas, comuns ao processo de senescência (GORDILHO et al., 2000). 
Quadro 1 - Qualidade no atendimento disponibilizados a pessoas idosas em instituições de saúde e domiciliares, no atendimento pré-hospitalar, humanização e saúde bucal

\begin{tabular}{|c|c|c|c|c|c|c|c|}
\hline $\begin{array}{l}\text { AUTOR/ } \\
\text { ANO }\end{array}$ & METODOS & $\begin{array}{l}\text { SUJEITOS DA } \\
\text { PESQUISA }\end{array}$ & $\begin{array}{l}\text { FAIXA } \\
\text { ETÁRIA }\end{array}$ & INSTITUIÇÃOO & $\begin{array}{l}\text { QUALIDADE NO } \\
\text { ATENDIMENTO }\end{array}$ & OBJETIVO & SUGESTÕES DO AUTOR \\
\hline $\begin{array}{l}\text { Bayliss et al. } \\
\text { (2015) }\end{array}$ & $\begin{array}{l}\text { Estudo de coorte } \\
\text { retrospectivo }\end{array}$ & $\begin{array}{l}12.200 \text { idosos } \\
\text { com } 3 \text { ou mais } \\
\text { condiçōes } \\
\text { crônicas. }\end{array}$ & - & Hospitalar & Satisfatório & $\begin{array}{l}\text { Avaliar o efeito positivo da } \\
\text { relação entre continuidade } \\
\text { do cuidado em na atenção } \\
\text { primária e especializada, se- } \\
\text { gundo visão do autor. }\end{array}$ & $\begin{array}{l}\text { A implantação de um sistema de in- } \\
\text { tegral de continuidade da assistência } \\
\text { que trará benefícios para assistência } \\
\text { primária e especializada. }\end{array}$ \\
\hline $\begin{array}{l}\text { Martin et al. } \\
\quad(2006)\end{array}$ & $\begin{array}{l}\text { Estudo } \\
\text { transversal }\end{array}$ & Idosos & $\geq 60$ & Hospitalar & Satisfatória & $\begin{array}{l}0 \text { papel do envelhecimento } \\
\text { populacional em internações } \\
\text { hospitalares realizadas pelo } \\
\text { (SUS) e algumas de suas con- } \\
\text { sequências para o nível local, } \\
\text { segundo a visão do autor. }\end{array}$ & $\begin{array}{l}\text { As internações, sempre que possível, } \\
\text { devem ser evitadas. Tanto pelo im- } \\
\text { pacto causado no sistema de saúde, } \\
\text { mas também pelos efeitos negativos } \\
\text { que impõem ao próprio paciente. } 0 \\
\text { sistema deve-se reestruturar, visando } \\
\text { à promoção da saúde, prevenção de } \\
\text { doenças, diagnóstico e tratamento } \\
\text { precoce das patologias crônicas e das } \\
\text { incapacidades associadas, no adulto } \\
\text { em geral especialmente no idoso. }\end{array}$ \\
\hline $\begin{array}{l}\text { Guerra, Giatti } \\
\text { e Lima-Costa } \\
\text { (2004) }\end{array}$ & $\begin{array}{c}\text { Estudo } \\
\text { quantitativo } \\
\text { descritivo }\end{array}$ & 17 Hospitais & $\geq 60$ & Hospitalar & Insatisfatório & $\begin{array}{l}\text { Monitorar a mortalidade } \\
\text { hospitalar em internações de } \\
\text { idosos como forma de avaliar } \\
\text { a qualidade da assistência, } \\
\text { segundo a visão do autor. }\end{array}$ & $\begin{array}{l}\text { Os resultados do presente trabalho } \\
\text { mostram que os diferenciais de ris- } \\
\text { co, entre os hospitais investigados, } \\
\text { podem servir como sinal de alerta e } \\
\text { ponto de partida para investigações } \\
\text { mais aprofundadas sobre a qualidade } \\
\text { da assistência oferecida ao idoso nos } \\
\text { estabelecimentos com maiores e per- } \\
\text { sistentes em números de mortalidade. }\end{array}$ \\
\hline $\begin{array}{l}\text { Barbosa et al. } \\
\text { (2005) }\end{array}$ & $\begin{array}{c}\text { Estudo } \\
\text { exploratório } \\
\text { artigo descritivo }\end{array}$ & $\begin{array}{l}3 \text { instituições } \\
\text { asilares. }\end{array}$ & $\begin{array}{c}60 \mathrm{a} 64 \mathrm{e} \\
\geq 80\end{array}$ & Asilos & Insatisfatório & $\begin{array}{l}\text { Discutir sobre a situação social } \\
\text { do idoso no Brasil, consideran- } \\
\text { do os aspectos demográficos, } \\
\text { epidemiológicos e psicos- } \\
\text { sociais com destaque para a } \\
\text { aposentadoria, a importância } \\
\text { da família e as relações inter- } \\
\text { pessoais, segundo a visão do } \\
\text { autor. }\end{array}$ & $\begin{array}{l}\text { Há necessidade de uma atenção urgen- } \\
\text { te à população ao sujeitos da pesquisa, } \\
\text { refletindo, discutindo e buscando } \\
\text { formas alternativas de integração so- } \\
\text { cial, convívio familiar e, sobretudo, } 0 \\
\text { envolvimento efetivo dos órgãos pú- } \\
\text { blicos, da saúde e da sociedade como } \\
\text { um todo. }\end{array}$ \\
\hline $\begin{array}{c}\text { Pinto e Von } \\
\text { Simson(2012) }\end{array}$ & $\begin{array}{c}\text { Estudo } \\
\text { exploratório } \\
\text { artigo descritivo }\end{array}$ & $\begin{array}{l}\text { Cumprimento } \\
\text { da legislaçãao } \\
\text { comparando } \\
\text { com instituições } \\
\text { de longa } \\
\text { permanência }\end{array}$ & $\geq 60$ & Asilos & Insatisfatório & $\begin{array}{l}\text { Apresentar um sumário da } \\
\text { legislação federal da Consti- } \\
\text { tuição de } 1998 \text { com atenção } \\
\text { às normas relativas à assistên- } \\
\text { cia em Instituições de Longa } \\
\text { Permanência para Idosos, } \\
\text { segundo visão do autor }\end{array}$ & $\begin{array}{l}\text { É necessário a inclusão das ILPIs no es- } \\
\text { copo das instituições sob inspeção das } \\
\text { Vigilâncias Sanitárias, reconhecendo } \\
\text { sua inclusão na esfera sanitária. Espe- } \\
\text { ra-se agora que essas agências capaci- } \\
\text { tem ainda mais seus efetivos para apri- } \\
\text { morar as regras e exercer a fiscalização } \\
\text { sobre esse tipo original de serviço, que } \\
\text { é simultaneamente sanitário e social }\end{array}$ \\
\hline $\begin{array}{c}\text { Marin et al. } \\
\text { (2010) }\end{array}$ & Estudo descritivo & 67 idosos & $\begin{array}{l}60 \text { a } 69 \\
\geq 80\end{array}$ & $\begin{array}{l}\text { Idoso/familiar/ } \\
\text { cuidador } \\
\text { domiciliar. }\end{array}$ & Satisfatório & $\begin{array}{l}\text { Verificar o perfil sócio-demo- } \\
\text { gráfico dos idosos e a assis- } \\
\text { tência que recebem após a } \\
\text { alta hospitalar da equipe da } \\
\text { Estratégia de Saúde da Famí- } \\
\text { lia (ESF), segundo a visão do } \\
\text { idoso. }\end{array}$ & $\begin{array}{l}\text { A ESF ainda precisa avançar na cons- } \\
\text { trução do novo modelo de atenção à } \\
\text { saúde, visto que,mesmo implantado, } \\
\text { ainda não desenvolveu o processo de } \\
\text { cuidado com vista a um atendimento } \\
\text { integral, pautado no vínculo e na res- } \\
\text { ponsabilização. } \\
\text { Acredita-se, no entanto, que, com os } \\
\text { investimentos na formação e quali- } \\
\text { ficação dos profissionais de saúde e } \\
\text { por meio das mudanças curriculares } \\
\text { nos cursos de graduação e da educa- } \\
\text { ção permanente e continuada, exista } \\
\text { a possibilidade de enfrentamento da } \\
\text { situação. }\end{array}$ \\
\hline
\end{tabular}




\begin{tabular}{|c|c|c|c|c|c|c|c|}
\hline $\begin{array}{c}\text { Floriani e } \\
\text { Schramm } \\
(2004)\end{array}$ & $\begin{array}{c}\text { Revisão } \\
\text { Bibliográfica }\end{array}$ & $\begin{array}{l}\text { Paciente/ } \\
\text { Famíliares/ } \\
\text { Cuidador } \\
\text { envolvidos no } \\
\text { AD/HC }\end{array}$ & $\begin{array}{l}70 \text { a } 74 ; \\
80 \text { a } 84 ; \\
85 \text { a } 89\end{array}$ & $\begin{array}{c}\text { Assistência } \\
\text { domiciliar } \\
\text { (ESF) }\end{array}$ & Insatisfatório & $\begin{array}{l}\text { Descrever os aspectos pro- } \\
\text { blemáticos e conflituosos, do } \\
\text { ponto de vista moral, a partir } \\
\text { de revisão da literatura que } \\
\text { aborda questões éticas em } \\
\text { relação ao } \mathrm{AD} \text {, com enfoque } \\
\text { centrado no idoso, segundo a } \\
\text { visão do autor }\end{array}$ & $\begin{array}{l}\text { Inclusão na Política Nacional do Idoso } \\
\text { com a criação da Assistência Domiciliar } \\
\text { Geriátrica. Um maior direcionamento } \\
\text { ético na implantação do atendimento } \\
\text { domiciliar, com políticas de proteção } \\
\text { ao paciente, à família e ao cuidador, } \\
\text { visando a aperfeiçoar a qualidade dos } \\
\text { programas oferecidos }\end{array}$ \\
\hline $\begin{array}{l}\text { Martins et al. } \\
\quad(2007)\end{array}$ & $\begin{array}{c}\text { Estudo } \\
\text { exploratório- } \\
\text { descritivo, com } \\
\text { abordagem } \\
\text { qualitativa }\end{array}$ & 11 idosos & $\begin{array}{c}70 \text { a } 74, \\
80 \text { a } 84 \text { e } \\
85 \text { a } 89\end{array}$ & $\begin{array}{l}\text { Assistência } \\
\text { domiciliar }\end{array}$ & Insatisfatório & $\begin{array}{l}\text { Identificar e classificar as ne- } \\
\text { cessidades de educação em } \\
\text { saúde dadas pela equipe da } \\
\text { UBS, apresentadas pelos cui- } \\
\text { dadores de idosos, baseadas } \\
\text { na Classificação Internacional } \\
\text { das Práticas de Enfermagem } \\
\text { em Saúde Coletiva, segundo } \\
\text { visão do autor }\end{array}$ & $\begin{array}{l}0 \text { apoio informal e familiar constitui } \\
\text { um dos aspectos fundamentais na } \\
\text { atenção à saúde desse grupo popula- } \\
\text { cional. Tais temas deverão ser objetos } \\
\text { de processos educativos e informativos } \\
\text { permanentes, em todos os níveis de } \\
\text { atuação do SUS, com a utilização dos } \\
\text { diversos recursos e meios disponíveis, } \\
\text { tais como:distribuição de cartillhas } \\
\text { e folhetos do Ministério da Saúde e } \\
\text { Secretarias Municipais e Estaduais de } \\
\text { Saúde;o desenvolvimento de cam- } \\
\text { panhas em programas populares de } \\
\text { rádio; veiculação de propagandas na } \\
\text { televisão; treinamento de agentes } \\
\text { comunitários de saúde e profissionais } \\
\text { integrantes da estratégia de saúde da } \\
\text { família para, no trabalho domiciliar, } \\
\text { estimular os cidadãos na adoção de } \\
\text { comportamentos saudáveis }\end{array}$ \\
\hline $\begin{array}{c}\text { Campos, } \\
\text { Vargas e } \\
\text { Ferreira (2014) }\end{array}$ & $\begin{array}{c}\text { Estudo } \\
\text { Iongitudinal } \\
\text { com modelo } \\
\text { hierárquico } \\
\text { Multidimensional }\end{array}$ & 2.052 idosos & $\geq 60$ & $\begin{array}{l}\text { Satisfação na } \\
\text { saúde bucal do } \\
\text { idoso. }\end{array}$ & Satisfatório & $\begin{array}{l}\text { Identificar as diferenças de } \\
\text { gênero em relação aos fato- } \\
\text { res que estão relacionados à } \\
\text { satisfação com saúde bucal, } \\
\text { segundo visão do idoso além } \\
\text { da prevalência de edentulis- } \\
\text { mo por gênero e faixa etária, } \\
\text { segundo a visão do idoso }\end{array}$ & $\begin{array}{l}\text { As ações integradas de promoção da } \\
\text { saúde e do bem-estar que abordam, os } \\
\text { importantes e principais fatores deter- } \\
\text { minantes da autopercepção da saúde } \\
\text { poderão fomentar para a qualidade de } \\
\text { vida dos idosos de forma significativa. } \\
\text { As discussões de gênero no envelheci- } \\
\text { mento precisam ser mais pesquisadas } \\
\text { em relação às condições e percepção } \\
\text { da saúde bucal, pois existem fatores de } \\
\text { cada grupo que podem influenciar nas } \\
\text { análises rotineiras. }\end{array}$ \\
\hline $\begin{array}{l}\text { Lima et al. } \\
(2010)\end{array}$ & $\begin{array}{l}\text { Revisão } \\
\text { Bibliográfica }\end{array}$ & $\begin{array}{l}\text { Humanização } \\
\text { em todo o } \\
\text { atendimento } \\
\text { público ao idoso } \\
\text { nos diversos } \\
\text { cenários. }\end{array}$ & - & A humanização & Insatisfatório & $\begin{array}{l}\text { Discute as práticas de assis- } \\
\text { tência, políticas, estratégias e } \\
\text { ações governamentais forma- } \\
\text { lizadas para a saúde refletindo } \\
\text { na atenção humanizada a } \\
\text { saúde do idoso, segundo visão } \\
\text { do autor }\end{array}$ & $\begin{array}{l}\text { Capacitar o profissional e o investimen- } \\
\text { to nas estruturas físicas dos locais de } \\
\text { atendimento ao idoso, são necessário } \\
\text { para adequada assistência e devem } \\
\text { contribuir para um viver mais saudável } \\
\text { a esses indivíduos, sendo também de } \\
\text { responsabilidade de todos através da } \\
\text { reivindicação do direito a um atendi- } \\
\text { mento humanizado. }\end{array}$ \\
\hline $\begin{array}{l}\text { Deslandes e } \\
\text { Souza (2010) }\end{array}$ & $\begin{array}{c}\text { Pesquisa } \\
\text { multicêntrica } \\
\text { de abordagem } \\
\text { quantitativa e } \\
\text { qualitativa }\end{array}$ & Idosos & $\geq 60$ & $\begin{array}{l}\text { Atenção pré- } \\
\text { hospitalar ao } \\
\text { idoso vítima } \\
\text { de violência e } \\
\text { acidentes }\end{array}$ & Satisfatório & $\begin{array}{l}\text { Analisa as características e a } \\
\text { operacionalização cotidiana } \\
\text { da atenção pré-hospitalar aos } \\
\text { idosos vítimas de violências } \\
\text { e acidentes de cinco capitais, } \\
\text { abordando quais obstáculos, } \\
\text { capacidades, e potencialida- } \\
\text { des, segundo visão do autor }\end{array}$ & $\begin{array}{l}\text { A notificação do caso de violência ao } \\
\text { idoso pode melhorar como pode piorar } \\
\text { sua prática e isso depende: da relação } \\
\text { médico/paciente; da sua qualidade de } \\
\text { vida; do controle do profissional para } \\
\text { decidir o que é melhor para o paciente. } \\
\text { Acredita-se que esses paradoxos po- } \\
\text { dem ser superados mediante } 0 \text { enfren- } \\
\text { tamento dos obstáculos apresentados }\end{array}$ \\
\hline Veras (2003) & $\begin{array}{l}\text { Pesquisa de } \\
\text { campo }\end{array}$ & 366 idosos & $\begin{array}{c}65 \text { a } 74 \\
75 \text { a } 79 \\
\text { e } 80 \text { a } \\
84 .\end{array}$ & Ambulatório & Insatisfatório & $\begin{array}{l}\text { Propor um fluxo de acesso } \\
\text { e definição de prioridades } \\
\text { em uma rede ambulatorial, } \\
\text { classificando os idosos em } \\
\text { diferentes grupos de risco de } \\
\text { fragilização, segundo visão } \\
\text { do autor }\end{array}$ & $\begin{array}{l}\text { Sugere-se testar a validade do método } \\
\text { de fluxo de acesso e definição de prio- } \\
\text { ridades na rede ambulatorial em um } \\
\text { estudo prospectivo }\end{array}$ \\
\hline
\end{tabular}


Esse fato desencadeia o crescimento das despesas com tratamentos médicos e hospitalares, ao mesmo tempo em que apresenta um desafio para as autoridades sanitárias, especialmente no que diz respeito a implantação e execução de novos modelos e métodos de planejamento, gerência e prestação de cuidados adequados (VERAS, 2003).

O estudo de Guerra (2004), contrasta o apresentado por Martin (2006) nos mostrando uma qualidade da assistência ao idoso no meio hospitalar insatisfatória, com elevado índice de mortalidades e abrindo caminho para investigação e execução de pesquisas aprofundadas no ambiente com maiores números de óbitos de idosos. Utilizando dados de mortes em hospitais de grande porte, o autor expõe condições desfavoráveis e semelhantes que levam a uma assistência com lacunas a um público tão prioritário e crítico.

Sendo de tamanha importância buscar avaliar dados de estudos sobre instituições de longa permanência, foi selecionado no trabalho, duas pesquisas sobre as condições de saúde e socioeconômicas dos idosos presentes em asilos no Brasil. Ambos seguem a mesma conclusão na sua avaliação da qualidade da assistência prestada, como sendo insatisfatórios, com condições precárias e privações ao seu usuário o que é condizente com a literatura.

As tensões sociais e psicológicas podem acentuar as deteriorações associadas ao processo de envelhecimento. Percebe-se, no indivíduo que envelhece, uma interação maior entre os estados psicológicos e sociais influenciando sua adaptação às mudanças. A habilidade pessoal de se envolver, de encontrar significado para viver, provavelmente influencia as transformações biológicas e de saúde (MENDES, 2005).

A situação familiar dos idosos brasileiros reflete o efeito cumulativo em eventos socioeconômicos, demográficos e de saúde ao longo dos anos, apresentando questões como o tamanho da prole, as separações, o celibato, a mortalidade, a viuvez, os recasamentos e as migrações, vão ocasionando no desenvolver das décadas tipos de arranjos familiares e domésticos, em que o morar sozinho, com parentes ou em asilos pode ser o resultado desses desenlaces (NERI, 1999).

Os asilos, geralmente, são locais com estrutura inapropriada as comuns e necessidades reais, sendo a forma mais antiga de atendimento ao idoso. Não ofertam serviços garantidos pela nossa Constituição e as políticas voltadas ao idoso como assistência social, cuidados básicos de higiene e alimentação. São locais que muitas vezes levam ao surgimento de relações críticas com dificuldades no contexto comunitário, indispensáveis à manutenção pela vida e pela construção de sua cidadania. Fora do seu ambiente familiar, este fica exposto ao favorecimento do isolamento, sua inatividade física e mental, levando a sérias consequências negativas à sua qualidade de vida.

Os trabalhos selecionados sobre asilos realizados por Barbosa et al. (2004), Pinto e Von Simson (2012) foram elaborados nas cidades de Natal - RN e nas demais cidades do Brasil respectivamente, fazendo comparativos com a literatura e as legislações existentes desde a Constituições de 1988. Ambos como já citados avaliam a qualidade como insatisfatória em conformidade com o que a literatura diz além de nos apresentar a visão de que forma o Brasil vem seguindo a passos lentos em concordância com a permanência do idoso em asilos. Sabendo que esse sistema até hoje não modificado, não dispõem de qualidade e eficiência, com grandes deficiências no que diz respeito a assistência prestada.

Pelo fato de lidarmos com uma população que tem aumentado em anos recentes, existe uma grande carência de profissionais treinados, com formação específica e cursos reconhecidos pela qualidade acadêmica. A Sociedade Brasileira de Geriatria e Gerontologia (SBGG) reconhece pouco mais de 500 médicos como especialistas em geriatria, enquanto nos dias atuais a população de idosos ultrapassa 15 milhões de brasileiros.

Dessa forma mais lacunas vão surgindo, questionamentos de como esses profissionais estão sendo treinados e capacitados para atender essa demanda populacional e de que forma deve ser feita a abordagem e onde há necessidade de mais investimentos. Tudo isso é importante e deve ser discutido e por isso faz-se necessário um olhar crítico as modalidades de atendimento ao idoso, buscando novas questões não deixando de enquadrar o domicilio nesse ambiente de tratamento que envolve também familiares, cuidadores e a própria equipe da ESF.

Os estudos feitos por Marin (2010), Floriani e Schramm (2004) e Martins et al. (2007) sobre atendimento ao idoso domiciliar de ambos os sexos, tem como avaliação insatisfatória. Utilizando como método avaliativo a análise de estudo bibliográfico. Todos nos mostram a necessidade acentuada da prestação de uma assistência adequada, a carência do conhecimento por parte dos seus cuidadores em questões básicas como interação medica- 
mentosa, prática de exercícios físicos etc. além do próprio agente comunitário de saúde (ACS) que faz o seu trabalho com certa carência não possuindo o apoio adequado para prestar $o$ atendimento direcionado nas suas atividades.

Existem situações em que o idoso busca o serviço de saúde ou mesmo necessita de uma assistência rotineira não só devido as comorbidades comuns à sua idade, mas vítimas de violência e acidentes que muitas vezes são sub-notificados. Deslandes e Souza (2010) discutem-se questões relativas ao atendimento pré-hospitalar móvel, das quais sobressai a desigualdade do tamanho das equipes e a sua falta de capacitação para identificar e atuar nos casos de violência contra os idosos, basicamente formadas por generalistas. Nem sempre elas contam com a necessária especialidade para o atendimento com quadros mais complexos de saúde, sendo visível o despreparo das equipes de como proceder desde a notificação assim como o seu atendimento.

Conforme observamos, o idoso necessita, devido a todo o seu processo de envelhecimento, de uma atenção diferenciada e especializada, pois este é o público que mais consome o serviço de saúde com alto custo e mesmo assim sabemos que os recursos existentes são ineficientes por ser muitas vezes mal estruturado o que diferencia de países mais desenvolvidos onde mesmo o idoso sendo o maior consumidor do serviço, a oferta é mais sólida e direcionada de forma adequada.

Foi assim selecionado um trabalho que aborda a assistência ambulatória adequada ao idoso, utilizando uma revisão literária, realizando a proposta da implantação de um instrumento de captação precoce e previsão dos agravos no ambiente de tratamento citado. $\mathrm{O}$ estudo mostrou ser notória a melhoria se aplicado a proposta do fluxo de acesso fazendo com que haja a hierarquização dos riscos contribuindo para um sistema eficaz e resolutivo. Utilizando um questionário em um guichê ambulatorial, a pesquisa traz a atual realidade ineficiente desse acesso, porém com proposta válida que deve ser considerada e experimentada substituindo assim o modelo atual existente (VERAS, 2003).

A saúde bucal na atenção à saúde está presente voltada a toda as populações desde criança, jovem e idade adulta, assim também como aos idosos. Muitas vezes falar em saúde bucal, se associa o idoso com edentulismo, ou seja, perda dentária ou a utilização de próteses, pois, na realidade da população brasileira, o público-alvo desse estudo, geralmente quando não possui ausência total de dentes, fazem uso de próteses desgastadas e sem manutenção adequada.

O último levantamento epidemiológico fornecido pelo Ministério da Saúde em 2010 apresenta uma situação crítica para os idosos brasileiros, com elevada perda dentária e edentulismo. Nesse estudo a avaliação da satisfação da saúde bucal do idoso foi considerada satisfatória pelo próprio idoso, fortemente influenciada pelo seu comportamento de saúde utilizando o modelo comportamental (CAMPOS; VARGAS; FERREIRA, 2014). O que confronta com os dados já apresentados da crítica situação de saúde bucal que esse público apresenta.

Durante a exposição dos estudos destacados, abordou-se a avaliação da qualidade na assistência ao idoso em diferentes ambientes de tratamento envolvendo o processo familiar, seu cuidador e o profissional da saúde, além dos altos custos que esse público demanda e das suas peculiaridades. Há outro elemento importante que envolve esse contexto, a humanização, sendo um ponto indispensável a ser discutido e avaliado, que se enquadra na linha de pesquisa abordada pelo autor desse trabalho.

Essa pesquisa aborda a proposta da pratica assistencial da atenção ao idoso de forma humanizada, onde o considerou segundo autor, insatisfatória. Elemento que se insere em uma realidade de angústias com a desvalorização das aposentadorias e pensões, com receios e depressões, com a falta de assistência e de atividades de lazer, com o abandono e isolamento em hospitais ou asilos, além de enfrentar ainda todo o tipo de dificuldades para assegurar alguma assistência por meio de planos de saúde muitas vezes ineficientes que os idosos brasileiros vivenciam (LIMA et al., 2010).

O desconhecimento, paralelo ao preconceito e ao desrespeito aos cidadãos da terceira idade somam-se à precariedade de investimentos públicos para atendimento às necessidades específicas da população idosa, a falta de estrutura e instalações adequadas, a carência de programas específicos e de recursos humanos, seja em quantidade ou qualidade (PARAHYBA; SIMÕES, 2006).

\section{Conclusão}

Como foi observado em grande maioria, as modalidades apresentadas de atendimento ao idoso existente deixam a desejar desde a falta de recurso, a capacitação de profissionais, observou-se também que os 12 estudos selecionados, apenas 5 apresentam qualidade satisfatória 
muitas vezes questionadas, pois os sujeitos da pesquisa possuem capacidades duvidosas por conta da idade e grau de instrução que põe em dúvida a confiabilidade do resultados como índice avaliativo, levando a crer que os 58,33\% de avaliação insatisfatória são de fato os de maior importância e compatibilidade com a literatura.

Atentemos ao número de publicações da temática abordada que vem diminuindo a cada ano, segundo o número de achados nas bases de dados, o que contradiz com o acentuado crescimento dessa população tão vulnerável refletindo certo desinteresse. Em todos os trabalhos, existem lacunas e sugestões de seus respectivos autores para melhorias na qualidade da assistência prestada, desde a visita mais frequente da equipe multidisciplinar a essa população assim como a forma de abordagem por parte dos enfermeiros e da equipe nas orientações e educação desses cuidadores. Muitos deles têm nível de escolaridade baixo, o que dificulta ainda mais a absorção das orientações resultados muitas vezes irreversíveis a essa população.

A maioria das amostras incluídas neste trabalho comportou-se de forma equivalente ao dos demais estudos abordados sobre atendimento ao idoso que mostra a necessidade de ser repensado buscando melhorias em todos os seus aspectos. Assim, é preciso que haja um olhar crítico da sociedade sobre como está sendo executada a assistência a essa população idosa refletindo em seus pontos positivos e negativos no que diz respeito a efetividade e a proteção dos usuários levando em consideração quais princípios estão inseridos na sua execução.

Falar sobre a temática de atendimento ao idoso é complexo devido ao leque de ambientes que esse está incluído, porém se faz necessário obtermos mais abordagens desse tema em cenários diversos, pois essa população senescente necessita de uma estruturação especializada desde seu domicilio, ao uso cotidiano dos serviços públicos e privados do país. Não sendo encontrado nenhum trabalho nas bases de dados pesquisadas com uma assistência de forma eficiente e contínua aqui no Brasil o que se torna preocupante devido ao boom gerontológico que o país está vivendo.

Apesar de constantes conferencias e atenção focadas no bem-estar da população idosa, evidenciada pelo número de políticas, estatutos e programas que garantem os seus direitos, há uma grade proporção de falhas na execução desses programas além de alguns terem sido elaborados em uma realidade incoerente com os dias atuais o que necessita ser repensadas imediatamente para que possam ser feitos as adaptações necessárias somadas a uma prática administrativa sólida dos recursos.

Como foi objetivado mostrar, vimos que a atenção em saúde do idoso existente no Brasil tem deixado muito a desejar além de desconhecimento por muitos das grandes consequências que essas mudanças e desatenção a esse público trará. Acreditando, assim, ser necessário que todos reflitam de como será daqui alguns anos com um contingente de pessoas na terceira idade consumindo a economia sustentada por uma minoria.

O poder público necessita com urgência da elaboração de projetos voltados ao idoso, criando acessibilidade ao mercado de trabalho que se encontra limitada a essa população, dando mais participação, melhorando a qualidade da assistência em saúde e garantindo assim a cidadania e vida adequada as legislações vigentes asseguram e que esse público da terceira idade tanto necessita e merece.

\section{Referências}

BAYLISS, E. A. et al. Effect of continuity of care on hospital utilization for seniors with multiple medical conditions in an integrated health care system. Annals of Family Medicine, Colorado, v. 13, n. 2, p. 123-129, mar./abr. 2015. doi: 10.1370/afm.1739.

BRASIL. Lei no. 8.842, de 4 de janeiro de 1994. Política nacional de saúde da pessoa idosa. Brasília, 1994. Disponível em: <http://www.planalto.gov.br/CCivil_03/leis/ L8842.htm>. Acesso em: 21 set. 2014.

BRASIL. Ministério da Saúde. Gabinete do Ministro. Portaria MS n. 702 de 12 de abril de 2002. Dispõe sobre a criação de mecanismos para a organização e implantação de Redes Estaduais de Assistência à Saúde do Idoso. Disponível em: <http://www.camara.gov.br/sileg/integras/239984.pdf>. Acesso em: 16 out. 2016.

BRASIL. Ministério da Saúde. Secretaria de Assistência à Saúde. Redes estaduais de atenção à saúde do idoso: guia operacional e portarias relacionadas. Brasília: Ministério da Saúde, 2002.

CAMPOS, A. C. V.; VARGAS, A. M. D.; FERREIRA, E. F. Satisfação com saúde bucal de idosos brasileiros: um estudo de gênero com modelo hierárquico. Cadernos de Saúde Pública, Rio de Janeiro, v. 30, n. 4, p. 757-773, abr. 2014. doi: 10.1590/0102-311X00088813. 
DESLANDES, S. F.; SOUZA, E. R. Atendimento pré-hospitalar ao idoso vítima de violência em cinco capitais brasileiras. Ciência \& Saúde Coletiva, Rio de Janeiro, v. 15 , n. 6 , p. $2775-2786$, set. 2010 . doi: $10.1590 /$ S141381232010000600015 .

FERREIRA, F. P. C.; BANSI, L. O.; PASCHOAL, S. M. P. Serviços de atenção ao idoso e estratégias de cuidado domiciliares e institucionais. Revista Brasileira de Geriatria e Gerontologia, Rio de Janeiro, v. 17, n. 4, p. 911-926, dez. 2014. doi: 10.1590/1809-9823.2014.1305.

FLORIANI, C. A.; SCHRAMM, F. R. Atendimento domiciliar ao idoso: problema ou solução. Cadernos de Saúde Pública, Rio de Janeiro, v. 20, n. 4, p. 986-994, jul./ago. 2004. doi: 10.1590/S0102-311X2004000400013.

GALVÃO, C. M.; SAWADA, N. O.; TREVIZAN, M. A. Revisão sistemática: recurso que proporciona a incorporação das evidências na prática da enfermagem. Revista Latino-Americana de Enfermagem, Ribeirão Preto, v. 12, n. 3, p. 549-56, maio/jun. 2004. doi: 10.1590/S010411692004000300014 .

GUERRA, H. L.; GIATTI, L.; COSTA, M. F. L. Mortalidade em internações de longa duração como indicador da qualidade da assistência hospitalar ao idoso. Epidemiologia e Serviços de Saúde, Brasília, v. 13, n. 4, p. 247-325, dez. 2004. doi: 10.5123/S1679-49742004000400007.

HOUAISS, A.; VILLAR, M. S. Dicionário da língua portuguesa. Rio de Janeiro: Objetiva, 2004.

LIMA, T. J. V. et al. Humanização na atenção à saúde do idoso. Saúde e Sociedade, São Paulo, v. 19, n. 4, p. 866-877, out./nov. 2010. doi: 10.1590/S0104-12902010000400013.

LOUVISON, M. C. P.; BARROS, S. Políticas públicas e envelhecimento: a construção de uma política de direitos e os desafios da atenção integral à saúde da pessoa idosa no SUS. BIS - Boletim do Instituto de Saúde, São Paulo, v. 47 , p. 53-55, abr. 2009.

MARIN, M. J. S. et al. Características sócio-demográficas do atendimento ao idoso após alta hospitalar na estratégia da saúde de família. Revista de Escola de Enfermagem USP, São Paulo, v. 44, n. 4, p. 962-968, dez. 2010. doi: 10.1590/S0080-62342010000400015.
MARTINS, J. J. et al. Necessidades de educação em saúde dos cuidadores de pessoas idosas no domicilio. Texto Contexto de Enfermagem, Florianópolis, v. 16, n. 2, p. 254-262, abr./jun. 2007. doi: 10.1590/S010407072007000200007.

MARTIN, G. B. et al. Assistência hospitalar à população idosa em cidade do sul do Brasil. Epidemiologia e Serviços de Saúde, Brasília, v. 15, n. 1, p. 59-65, jan./mar. 2006. doi: 10.5123/S1679-49742006000100005.

MENDES, M. R. S. S. B. et al. A situação social do idoso no Brasil: uma breve consideração. Acta Paulista de Enfermagem, São Paulo, v. 18, n. 4, p. 422-426, out./dez. 2005. doi: 10.1590/S0103-21002005000400011.

NERI, A. L. Velhice e sociedade. Campinas: Alínea, 1999.

NETTO, M. L. F. Aspectos biológicos e fisiológicos do envelhecimento humano e suas implicações na saúde do idoso. Pensar a Prática, Goiânia, v. 7, p. 75-84, mar. 2004. doi: 10.5216/rpp.v7i1.67.

ORGANIZAÇÃO PAN-AMERICANA DE SAÚDE; ORGANIZAÇÃO MUNDIAL DE SAÚDE. Envelhecimento Ativo: uma política de saúde. 2002. Disponível em: $<$ http://bvsms.saude.gov.br/bvs/publicacoes/envelhecimento_ativo.pdf $>$. Acesso em: 18 set. 2014.

PARAHYBA, M. I.; SIMÕES, C. C. S. A prevalência de incapacidade funcional em idosos no Brasil. Ciência \& Saúde Coletiva, Rio de Janeiro, v. 11, n. 4, p. 967-974, out. /dez. 2006. doi: 10.1590/S1413-81232006000400018.

PINTO, S. P. L. C.; VON SINSON, O. R. M. Instituições de longa permanência para idosos no Brasil: sumário da legislação. Revista Brasileira de Geriatria e Gerontologia, Rio de Janeiro, v. 15, n. 1, p. 169-174, jan./mar. 2012. doi: 10.1590/S1809-98232012000100018.

PIOVESAN, A; TEMPORINI, E. R. Pesquisa exploratória: procedimento metodológico para o estudo de fatores humanos no campo da saúde pública. Revista de Saúde Pública, São Paulo, v. 29, n. 4, p. 318-315, ago. 1995. doi: 10.1590/S0034-89101995000400010. 
PRADO, S. D. et al. A pesquisa sobre envelhecimento humano no Brasil: grupos e linhas de pesquisa. Ciências \& Saúde Coletiva, Rio de Janeiro, v. 9, n. 1, p. 57-68, jan./ mar., 2004. doi: 10.1590/S1413-81232004000100006.

VERAS, R. Em busca de uma assistência adequada à saúde do idoso: revisão da literatura e aplicação de um instrumento de detecção precoce e de previsibilidade de agravos. Cadernos de Saúde Pública, Rio de Janeiro, v. 19, n. 3, p. 705-715, maio/jun. 2003. doi: 10.1590/S0102$311 \mathrm{X} 2003000300003$.
VERAS, R. Fórum Envelhecimento populacional e as informações de saúde do PNAD: demandas e desafios contemporâneos. Introdução. Cadernos de Saúde Pública, Rio de Janeiro, v. 23, n. 10, p. 2463-2466, out. 2007. doi: 10.1590/S0102-311X2007001000020. 